\title{
Triggering sequence of large aftershocks of the Mid Niigata prefecture, Japan Earthquake in 2004 by static stress changes
}

\author{
Masatoshi Miyazawa ${ }^{1}$, Jim Mori ${ }^{1}$, Yoshihisa Iio ${ }^{1}$, Takuo Shibutani ${ }^{1}$, Satoshi Matsumoto ${ }^{2}$, Hiroshi Katao $^{1}$, \\ Shiro Ohmi ${ }^{1}$, and Kin'ya Nishigami ${ }^{1}$ \\ ${ }^{1}$ Disaster Prevention Research Institute, Kyoto University, Uji, Kyoto 611-0011, Japan
${ }^{2}$ Institute of Seismology and Volcanology, Faculty of Science, Kyushu University, Shimabara, Nagasaki 855-0843, Japan
}

(Received February 24, 2005; Revised April 25, 2005; Accepted September 3, 2005)

\begin{abstract}
Following the Mid Niigata prefecture Earthquake $\left(\mathrm{M}_{\mathrm{JMA}}\right.$ 6.8) in 2004, 4 large aftershocks $\left(\mathrm{M}_{\mathrm{JMA}}\right.$ 6.3, 6.0, 6.5, 6.1) occurred: three within 40 minutes and one after 4 days. We examine the possibility for the triggering of this sequence of large aftershocks by static stress changes. For the close spatial triggering, it is important to have information about the fault geometries, slip distribution, and focal mechanisms. We determine the fault plane orientations from the aftershock distributions. Slip distributions of the mainshock and the largest aftershock are obtained by seismic waveform inversions of local strong-motion records. Mechanisms for the events are taken from MT solutions. The temporal variations of Coulomb failure function changes $(\triangle \mathrm{CFF})$ are calculated on the fault planes of the aftershocks before their rupture. Positive $\Delta$ CFF values $(0.06-0.3 \mathrm{MPa})$ are obtained around the hypocenters on the fault planes, indicating the possibility that static triggering from the main event and following aftershocks can explain the occurrence of subsequent aftershocks.
\end{abstract}

Key words: Seismic waveform inversion, source process, Coulomb failure function changes, static triggering.

\section{Introduction}

The 2004 Mid Niigata prefecture Earthquake ( $\left.\mathrm{M}_{\mathrm{JMA}} 6.8\right)$ occurred at the depth of $11 \mathrm{~km}$ in central Japan on October 23, 2004 (17:56 UT+09), and was followed by 4 relatively large $\left(\geq \mathrm{M}_{\mathrm{JMA}} 6\right)$ aftershocks (Table 1$)$. Within the 40 minutes after the mainshock, the first large aftershock $\left(\mathrm{M}_{\mathrm{JMA}}\right.$ 6.3) occurred at 18:03, the second $\left(\mathrm{M}_{\mathrm{JMA}} 6.0\right)$ at 18:11 and the third ( $\mathrm{M}_{\mathrm{JMA}}$ 6.5) at 18:34. On October 27 at 10:40, the fourth large aftershock occurred with a magnitude of $\mathrm{M}_{\mathrm{JMA}}$ 6.1. These aftershocks have unexpectedly large magnitudes compared to the mainshock, since empirically the largest aftershock is usually a magnitude unit smaller than the mainshock. The aftershock distribution (Kato et al., 2005; Shibutani et al., 2005) shows that their fault geometries are very complicated, with fault planes parallel and conjugate to the mainshock fault plane. Understanding of the triggering process for these aftershocks can tell us about the temporal changes of the stress field in the region and seismic process of the subsequent activity.

We study the relationship between the mainshock and aftershocks by static stress changes. Temporal variations of Coulomb failure function changes $(\triangle \mathrm{CFF}$ ) (or Coulomb failure stress changes) are calculated to investigate the timedependent changes of the stress field due to occurrences of the mainshock and following aftershocks. The temporal $\triangle \mathrm{CFF}$ is capable of explaining static triggering of subsequent events (e.g., Papadimitriou, 2002). We do not consider the many aftershocks less than $\mathrm{M}_{\mathrm{JMA}} 6$, since large

Copyright (c) The Society of Geomagnetism and Earth, Planetary and Space Sciences (SGEPSS); The Seismological Society of Japan; The Volcanological Society of Japan; The Geodetic Society of Japan; The Japanese Society for Planetary Sciences; TERRAPUB. earthquakes should have much larger effects on the surrounding stress field. The fault planes are determined by the aftershock distributions of Shibutani et al. (2005) (Fig. 1). In order to calculate the temporal static stress changes by examining $\triangle \mathrm{CFF}$ due to fault dislocations, the focal mechanism and slip distribution are needed. For the two largest events, the mainshock $\left(\mathrm{M}_{\mathrm{JMA}}\right.$ 6.8) and the largest aftershock $\left(\mathrm{M}_{\mathrm{JMA}}\right.$ 6.5), an assumption of uniform slip over an assumed fault area is inappropriate. We consider slip distributions on these fault planes, similar to Toda and Stein (2003) who explained static triggering of a $\mathrm{M}_{\mathrm{JMA}} 6.4$ event by the neighboring $\mathrm{M}_{\mathrm{JMA}} 6.6$ event two month before, in southwest Kyushu, Japan in 1997. For the remaining three aftershocks, we assume a uniform slip, because they have small fault areas compared to the two other larger events, and for the focal mechanism we use the Moment Tensor (MT) solutions by the National Research Institute for Earth Science and Disaster Prevention (NIED) (Table 1).

\section{Slip Distributions of Mainshock and Largest Aftershock}

The slip distributions of the two large events are determined by a multi-time window waveform inversion (Hartzell and Heaton, 1983). We use three component (UD, NS, EW) velocity waveforms of local strong-motion, filtered from 1 to $20 \mathrm{sec}$, recorded by K-NET and KiK-net, which are operated by NIED. We use the same set of 6 stations for both the mainshock and aftershock, as shown by triangles in Fig. 1(a). For the inversions, the fault plane of the mainshock is divided into $6 \times 10$ subfaults of $3 \mathrm{~km} \times$ $3 \mathrm{~km}$ size (Fig. 2(a)), and the fault plane of the largest aftershock is divided into $6 \times 7$ subfaults of $2 \mathrm{~km} \times 2 \mathrm{~km}$ 
Table 1. Mechanisms of the mainshock and large aftershocks from Japan Metrological Agency (JMA), NIED and Shibutani et al. (2005)

\begin{tabular}{lccccccc}
\hline No. of aftershock & Origin time (GMT+09) & $\mathrm{M}_{\mathrm{JMA}}$ & $\mathrm{M}_{\mathrm{w}}$ & strike [deg] & dip [deg] & rake [deg] & slip [m] \\
\hline & $10.2317: 56: 00$ & 6.8 & 6.6 & 212 & 47 & - & - \\
$\# 1$ & $10.2318: 03: 13$ & 6.3 & 5.9 & 218 & 47 & 107 & 0.8 \\
$\# 2$ & $10.2318: 11: 56$ & 6.0 & 5.7 & 20 & 58 & 70 & 0.7 \\
$\# 3$ & $10.2318: 34: 06$ & 6.5 & 6.3 & 221 & 59 & $(94)$ & - \\
$\# 4$ & $10.2710: 40: 50$ & 6.1 & 5.8 & 18 & 32 & 73 & 0.7 \\
\hline
\end{tabular}

(a)

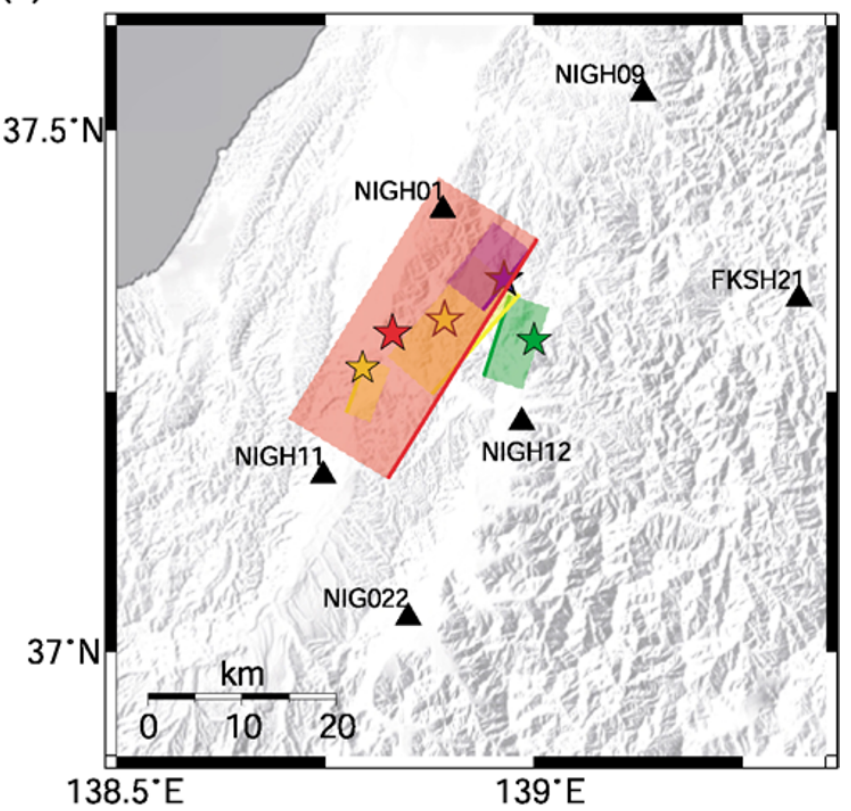

(b)

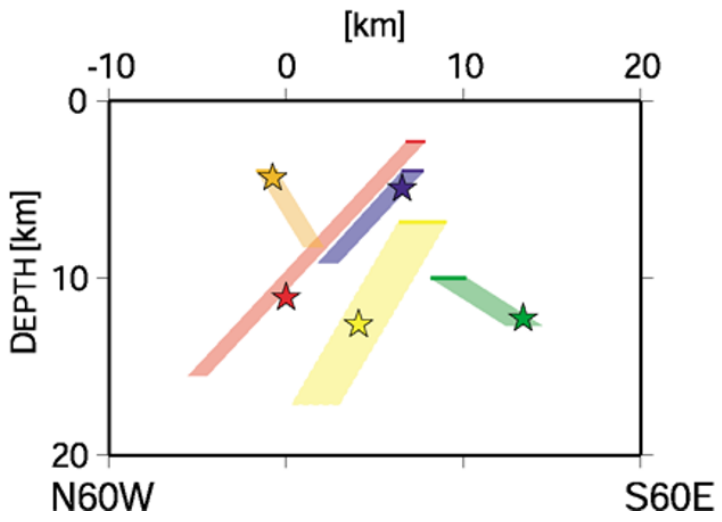

Fig. 1. Map view (a) and cross section (b) of the locations and orientations of fault planes of the mainshock and 4 large aftershocks (Table 1). Stars show the hypocenter locations. The mainshock is in red, the aftershock $\# 1$ in blue, \#2 in orange, \#3 in yellow, and \#4 in green. K-NET and KiK-net observation stations used in this study are indicated by triangles.

size (Fig. 2(b)). On each subfault, there are 6 triangular slip rate functions with a width of $0.6 \mathrm{sec}$ at $0.3 \mathrm{sec}$ intervals. Slip angles are constrained to a range of 70 to 110 deg. Green functions for each subfault are calculated using the program by Takeo (1987) with a velocity structure derived from analysis of aftershock locations (Shibutani et al., 2005). The solutions are obtained using a least-square inversion with a positivity constraint (Lawson and Hansen, 1974) on the slip vectors. We tried several orientations of faults, rupture start points, and rupture velocities.

Figure 2 shows the determined slip distributions of the mainshock (a) and the largest aftershock (b) using a rupture velocity of $2.0 \mathrm{~km} / \mathrm{s}$. Figure 3 shows the observed data (solid lines) and modeled seismograms (dotted lines) for the mainshock (a) and the largest aftershock (b). The moment obtained for the mainshock is $9.8 \mathrm{e}+25$ dyne- $\mathrm{cm}\left(\mathrm{M}_{\mathrm{w}} 6.6\right)$ and 2.1e +25 dyne-cm $\left(\mathrm{M}_{\mathrm{w}}\right.$ 6.2) for the largest aftershock which are consistent with the MT solutions $\left(\mathrm{M}_{\mathrm{w}} 6.6\right.$ and 6.3) by NIED (Table 1$)$.

For the mainshock the rupture starts $1 \mathrm{~km}$ above the hypocenter by Shibutani et al. (2005) to explain the observations, while the fault plane is still consistent with the aftershock distributions. The slip spreads out laterally and has the largest value around the hypocenter with a value of 3.9 $\mathrm{m}$. Other large slips are found around in deep and shallow regions to the northeast of the hypocenter. The result is similar to the other studies using the same data set (e.g., Honda et al., 2005). Also there is a good agreement between the observed and synthetic seismograms. For both the mainshock and aftershock there is a mismatch of amplitude at NIGH11, which may be due to the relatively soft site conditions at that station.

For the aftershock, the slip appears to propagate laterally in southwestern direction from the hypocenter. Synthetic waveforms for the aftershock appear to explain the observations. The slip from this aftershock has a smaller effect on calculation of $\triangle \mathrm{CFF}$ compared with the mainshock in this study (Fig. 4).

\section{Temporal Static Stress Changes}

We calculate temporal variations of $\Delta \mathrm{CFF}$ for the faults planes of the 4 aftershocks prior to their rupture. $\triangle \mathrm{CFF}$ is expressed as

$$
\Delta \mathrm{CFF}=\Delta \tau+\mu^{\prime} \Delta \sigma_{n}
$$

where $\Delta \tau$ is the shear stress change across a fault in the area of interest and takes positive value if the increase is in the same direction as the slip, $\mu^{\prime}$ is the apparent coefficient of friction including pore pressure effects, and $\Delta \sigma_{n}$ is the normal stress change, which is positive for traction across the fault. If $\triangle \mathrm{CFF}$ for a fault takes on positive/negative values, a source with the appropriate fault mechanism is easy/difficult to be triggered. We assume the rigidity $=$ $30 \mathrm{GPa}$ and $\mu^{\prime}=0.4$. We tested other values of $\mu^{\prime}=$ $0.2,0.6$ and 0.8 , however no significant differences were found among the results. Spatial stress changes due to the earthquakes are calculated by the method of Okada (1992). 
(a)

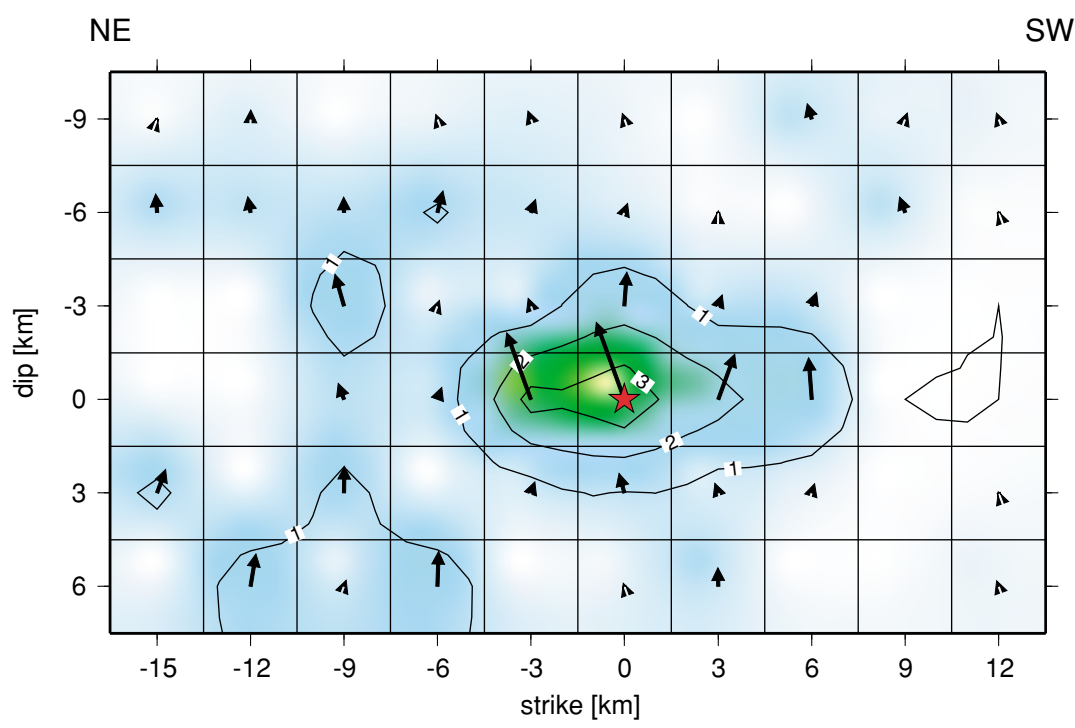

(b)

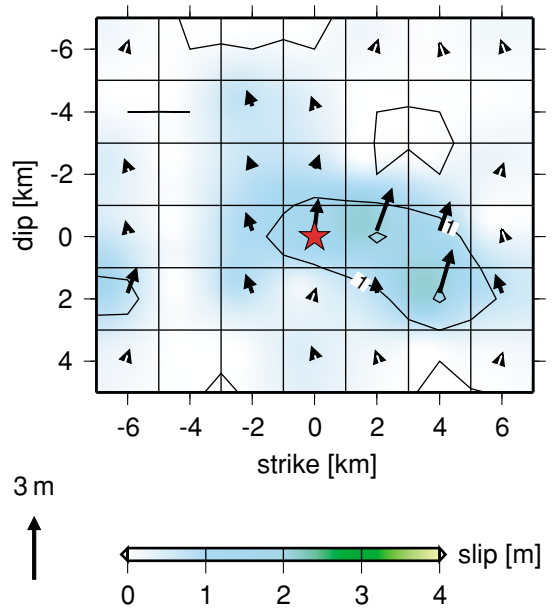

Fig. 2. Slip distributions of the mainshock (a) and the largest aftershock (b). The fault planes are divided into $6 \times 10$ subfaults for the mainshock and $6 \times 7$ subfaults for the aftershock, on which slip vectors are indicated. The orientations of fault planes are shown in Fig. 1 and listed in Table 1 . Red stars are the hypocenters.

(a)
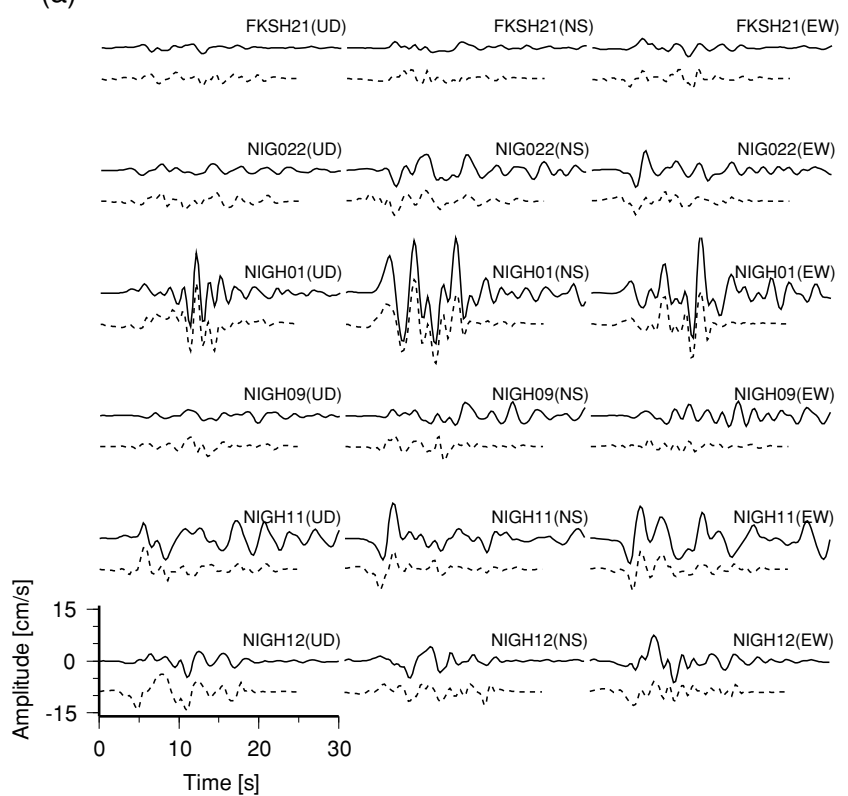

(b)
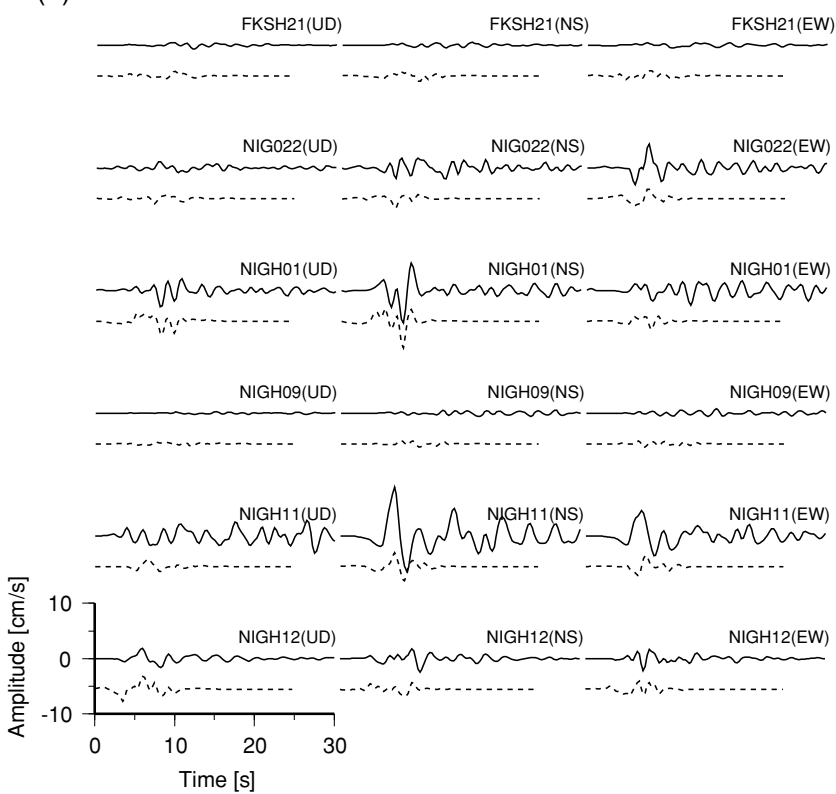

Fig. 3. Three components (UD, NS, EW) of velocity seismograms for the mainshock (a) and the largest aftershock (b). The observed waveforms are indicated by solid lines and the synthetic waveforms by dotted lines. The locations of the stations are shown in Fig. 1(a).

Static stress changes from the mainshock and the largest aftershock are calculated using the slip distributions obtained above (Fig. 2 and Table 1). For the other aftershocks we used the parameters in Table 1, where slip values are estimated from the fault area and the moment magnitude $M_{w}$.

Figure 4 shows the temporal values of $\triangle \mathrm{CFF}$ on the extended fault planes of each of the 4 large aftershocks. The figures across a row show the accumulated stress change following the mainshock and each large aftershock. The values are projected onto horizontal planes and areas above the ground surface are shown in white. The fault planes are indicated in black (solid and broken) lines and the epicenters by black stars. The white boxes show the fault planes of the events that are used to calculate the stress change. The green to red regions indicate areas where large positive $\triangle \mathrm{CFF}$ values are observed and the blue regions correspond to negative values.

The $\triangle \mathrm{CFF}$ distribution for the first aftershock (\#1) due to 


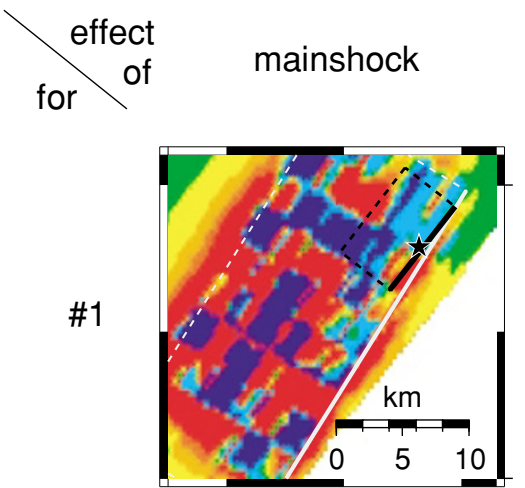

mainshock
$\&$
1 aftershock

mainshock

\&

2 aftershocks mainshock

\&

3 aftershocks

$37.4^{\circ}$

\section{$37.2^{\circ}$}

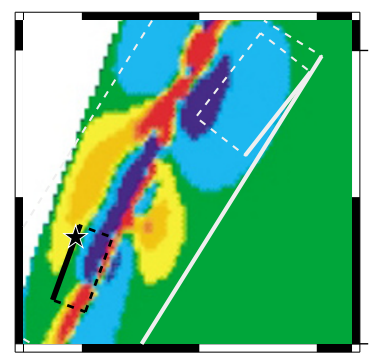

$37.2^{\circ}$

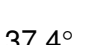

$37.4^{\circ}$
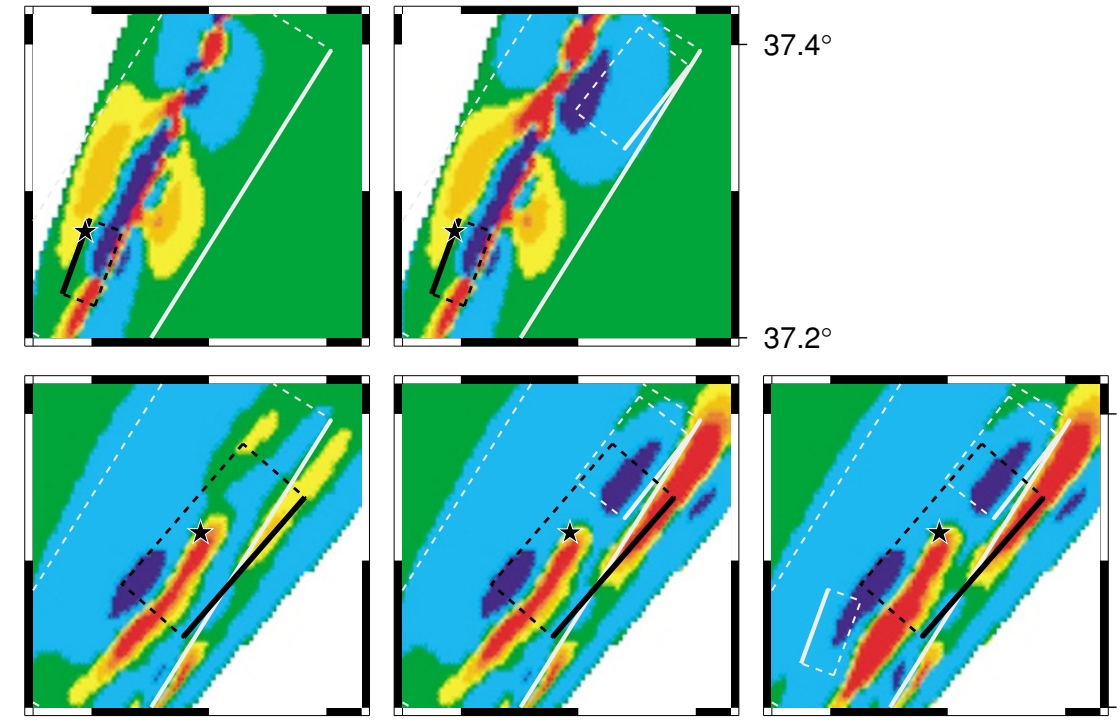

$37.4^{\circ}$
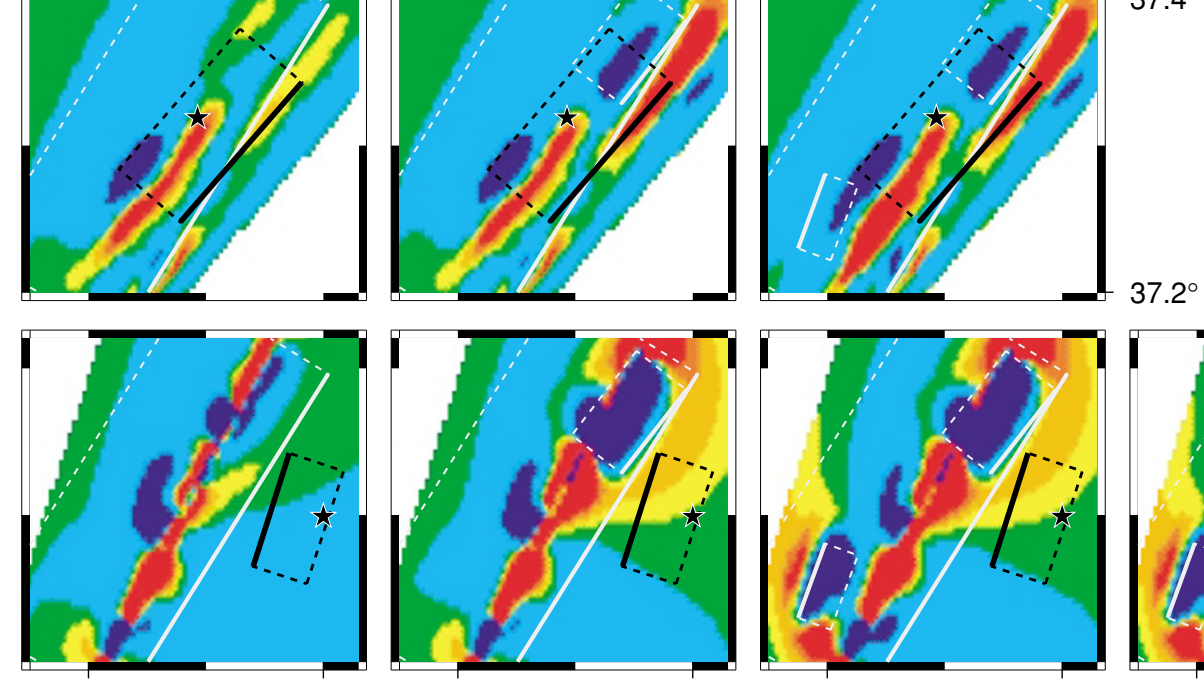

$138.8^{\circ}$
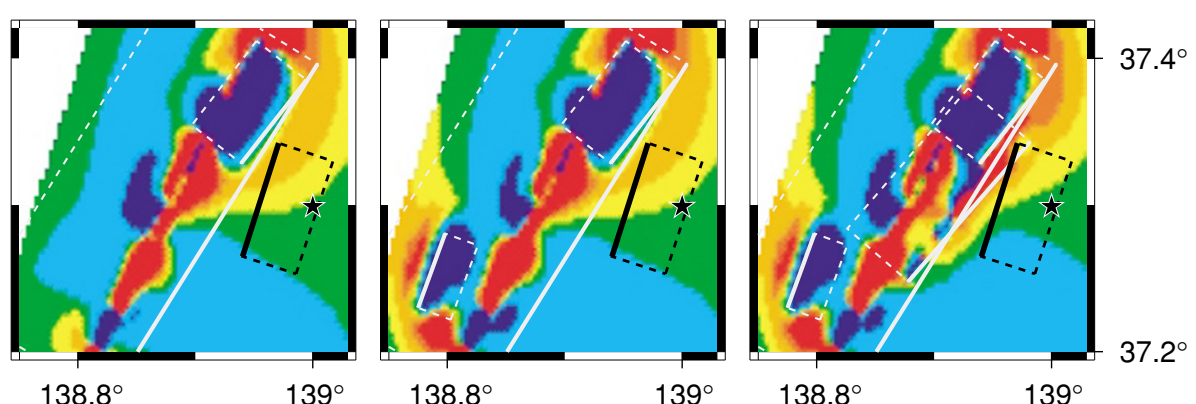

Fig. 4. Temporal variations of $\triangle \mathrm{CFF}$ values for the fault planes of the aftershocks (\#1-\#4 in Table 1), caused by the mainshock and preceding aftershocks. Fault planes and the epicenters are indicated by black boxes and stars, respectively. White boxes show fault planes of the events that are used to calculate $\triangle \mathrm{CFF}$ values.

the mainshock is shown in the top row in Fig. 4. The fault plane for this event is almost on the fault of the mainshock (Fig. 1). In this case for two very close fault planes, $\triangle \mathrm{CFF}$ depends strongly on the details of the mainshock slip distribution. However, we can infer that most regions on and near the fault plane of the mainshock show positive $\triangle \mathrm{CFF}$ values except for the large slip regions (Fig. 2(a)), because the aftershock has a mechanism similar to the mainshock.

The second aftershock (\#2) occurred on a fault plane conjugate to the mainshock (Fig. 1(b)). The static stress perturbations on the fault plane (black box) before its occurrence (second row in Fig. 4), were largely caused by the main event. The effects of the first aftershock (\#1) are small because it occurred at some distance on the opposite side of the region. $\triangle \mathrm{CFF}$ values are positive and large from the deep southern region to the shallow northern region. The rupture did not appear to start from the area of large $\Delta \mathrm{CFF}$ values, but in a shallow area with positive but relatively small values $(0.1 \mathrm{MPa})$.

For the largest aftershock (\#3) which had a similar orientation to the main fault (Fig. 1(b)), we calculated the $\triangle \mathrm{CFF}$, assuming the rake angle is 94 degree based on the MT solution (Table 1). The main event has a major influence on the $\triangle \mathrm{CFF}$ values (third row in Fig. 4) and the large slips in Fig. 2(a) cause the significant variation in pattern near the hypocenter. Around the hypocenter, the $\triangle \mathrm{CFF}$ values are positive $(0.1-0.3 \mathrm{MPa})$, while in the deeper and northeastern regions, the values are largely negative. The hypocenter is located on the northeastern edge of the large positive region, which includes the areas of large slip. 
On the plane of the fourth aftershock (\#4), which is also a fault conjugate to mainshock and aftershocks (\#1 and \#3), areas having positive $\triangle \mathrm{CFF}$ values gradually changed due to the mainshock and aftershocks (\#1 and \#3). Positive $\triangle \mathrm{CFF}$ values, including the hypocenter, are observed in the northern part and negative values in the south (fourth row in Fig. 4). After the third aftershock (\#3), around the hypocenter on the deeper portion of the fault, the value is relatively small $(0.06 \mathrm{MPa})$ compared with the shallow region. As in the case of the second aftershock (\#2), the rupture seems to have started from an area with positive, but low, $\triangle \mathrm{CFF}$ values.

\section{Discussion and Conclusions}

Our calculations show that the hypocenters of all of the larger aftershocks (except the first aftershock), various parts of their fault planes, and the large slip region of the largest aftershock, all had positive $\triangle \mathrm{CFF}$ value before their occurrences. For the first aftershock, since we could not reliably calculate static stress change values, because of the close proximity to the mainshock. The results suggest that the triggering of the larger aftershocks can be explained by static stress changes from the mainshock and preceding aftershocks.

The ruptures of the aftershocks did not always start from regions with the highest values of $\triangle \mathrm{CFF}$ on the fault, but sometimes in regions that had low but positive values $(0.06-$ $0.3 \mathrm{MPa}$ ). The rupture may occur on the fault plane, which includes positive static stress perturbations, but the starting point of the rupture does not seem to depend on the distribution of the values, as long as $\Delta \mathrm{CFF}>0$. Even considering the possible errors in locations of the fault planes, we would not have significantly different results, and much of the area of the aftershock fault planes include the regions of $\triangle \mathrm{CFF}$ $>0$. Since the hypocenters are located in regions with positive $\triangle \mathrm{CFF}$ values, these results support the possibility of static triggering.
Acknowledgments. This research was supported by the Japanese Ministry of Education, Culture, Sports, Science and Technology (MEXT) 21st Century COE Program for DPRI, Kyoto University (No. 14219301, Program Leader: Prof. Yoshiaki Kawata) and MEXT Special Coordination Funds for Promoting Science and Technology. We used K-NET and KiK-net data and MT solutions provided by NIED.

\section{References}

Hartzell, S. and T. Heaton, Inversion of strong ground motion and teleseismic waveform data for the fault rupture history of the 1979 Imperial Valley, California, earthquake, Bull. Seismol. Soc. Am., 73, 1553-1583, 1983.

Honda, R., S. Aoi, N. Morikawa, H. Sekiguchi, T. Kunugi, and H. Fujiwara, Ground motion and rupture process of the 2004 mid Niigata prefecture earthquake obtained from strong motion data of K-NET and KiK-net, Earth Planet Space, 57, 527-532, 2005.

Kato, A., E. Kurashimo, N. Hirata, S. Sakai, T. Iwasaki, and T. Kanazawa, Imaging the source region of the 2004 mid-Niigata prefecture earthquake and the evolution of a seismogenic thrust-related fold, Geophys. Res. Lett., 32, L07307, doi:10.1029/2005GL022366, 2005.

Lawson, C. L. and R. J. Hansen, Solving Least-Squares Problems, Prentice Hall, Inc., Englewood Cliffs, New Jersey, 340 pp, 1974.

Okada, Y., Internal deformation due to shear and tensile faults in a halfspace, Bull. Seism. Soc. Am., 82, 1018-1040, 1992.

Papadimitriou, E. E., Mode of strong earthquake recurrence in the central Ionian Islands (Greece): possible triggering due to Coulomb stress changes generated by the occurrence of previous strong shocks, Bull. Seism. Soc. Am., 92, 3293-3308, 2002.

Shibutani, T., Y. Iio, S. Matsumoto, H. Katao, T. Matsushima, S. Ohmi, F. Takeuchi, K. Uehira, K. Nishigami, B. Enescu, I. Hirose, Y. Kano, Y. Kohno, M. Korenaga, Y. Mamada, M. Miyazawa, K. Tatsumi, T. Ueno, H. Wada, and Y. Yukutake, Aftershock distribution of the 2004 Mid Niigata Prefecture Earthquake, Earth Planet Space, 57, 545-549, 2005.

Takeo, M., An inversion method to analyze the rupture processes of earthquakes using near-field seismograms, Bull. Seismol. Soc. Am., 77, 490513, 1987.

Toda, S. and R. Stein, Toggling of seismicity by the 1997 Kagoshima earthquake couplet: A demonstration of time-dependent stress transfer, J. Geophys. Res., 108, 2567, doi:10.1029/2003JB002527, 2003.

M. Miyazawa (e-mail: linen@eqh.dpri.kyoto-u.ac.jp), J. Mori, Y. Iio, T. Shibutani, S. Matsumoto, H. Katao, S. Ohmi, and K. Nishigami 